\title{
Comparative Analysis of Three-Phase Single Active Bridge DC-DC Converter with Different Mode of Conduction with Transformer Vector Groups
}

\author{
Mohsin Raza Mahesar*, Mukhtiar Ahmed Mahar, Abdul Sattar Larik and \\ Muzamil Hussain Solangi \\ Department of Electrical Engineering, Mehran University of Engineering Technology \\ Jamshoro, Pakistan
}

\section{Article Type: Article \\ Article Citation: Mohsin Raza Mahesar, Mukhtiar Ahmed Mahar, Abdul Sattar Larik and Muzamil Hussain Solangi. Comparative analysis of three phase single active bridge $D C-D C$ converter with different mode of conduction with transformer vector groups. Indian Journal of Science and Technology. 2020; 13(06), 630-645. D0l: 10.17485/ijst/2020/v013i06/149543}

Received date: December 10, 2019

Accepted date: January 16, 2020

*Author for correspondence: Mohsin Raza Mahesar mahesar85@gmail.com?Department of Electrical Engineering, Mehran University of Engineering Technology Jamshoro, Pakistan

\begin{abstract}
Background/objectives: This research study compares the performance of a three-phase single active bridge DC-DC converter with several operating modes along with vector groups in order to present the importance and applications of transformer vector groups in the electrical network system. Methods/statistical analysis: In order to analyze and compare the operating characteristics of three-phase single active bridge converter with vector groups of transformer. Initially, we made a detailed study of vector groups of transformers through literature review. Then the development of simulation model of three-phase single active bridge DC-DC converter with transformer vector groups while operating with different operating modes of three-phase inverter by using MATLAB/SIMULINK software was made. Findings: We investigated Total Harmonic Distortion (THD) in terms of voltage and current waveforms with both resistive and inductive load of SAB3 converter with the different transformer vector group while operating with different modes of conduction, i.e., 120, 150, and 180. Improvements: Undoubtedly, today's world is moving towards replacing fossil fuels with renewable energy resources. Three-phase single active bridge DC-DC converters are widely advantageous. From the simulated results, it is clear that at 150-operating mode, the SAB3 generated fewer harmonics in terms of voltage and current for both resistive and inductive load as compared to other operating modes.
\end{abstract}

Keywords: DC-DC Converter, Harmonics, Total Harmonic Distortion (THD), Three-Phase Single Active Bridge DC-DC Converter (SAB3). 


\section{Introduction}

In recent decades, high frequency and high-power DC-DC converters have been used because of their outrageous results and significance in a few regions of the energy sector such as distribution grids, renewable energy sector, energy storage system electric vehicles, and data centers. DC-DC converters have very wide industrial applications and in particular, the single active bridge (SAB3) converter is an advanced type of DC-DC converter [1]. SAB3 converter due to its compact size and attractive features, is used in high power applications such as high voltage direct current (HVDC), photovoltaic systems, and wind turbines. The SAB3 shown in Figure 1 is the unidirectional version of the well-known high-power density bidirectional Dual Active Bridge (DAB) for high power applications. Presently, various system-level topologies exist for offshore wind parks [2]. These topologies generally incorporate an AC collection grid and an AC- or a DC (HVDC) transmission line from the wind park to the shore, depending on the distance. The single active bridge is a buck derived topology that delivered power from the source to the load [3]. Harmonics generated due to the switching of solid-state switches in the SAB3 when it operates over a large voltage and load range at a constant frequency, thus for a specific application, a specific vector group gives optimum results [4]. Harmonics analysis and its mitigation reliably and cost-effectively are one of the major concerns of researchers. Commonly used mitigation techniques include linear chocks, isolating transformers, passive filters phaseshifting transformers [5], and active filters [6]. There are various studies on harmonics mitigation that are found in literature which analyzed the performance and the impact on power quality when linked with SAB3 through three-phase power transformer [7]. In spite of many harmonics controlling schemes, a transformer is always utilized to bring down the supply voltage at a handling capability of power electronic devices. There are fourteen (14) vectors groups of transformers that will be discussed in the coming sections. Literature shows the harmonics compressibility limit of some of the vector groups of transformers [8]. Harmonics generated by different nonlinear utilities are different, thus for a specific application, a specific vector group would give optimum results. Due to the switching of power devices in three-phase inverters, the harmonics are generated and when these

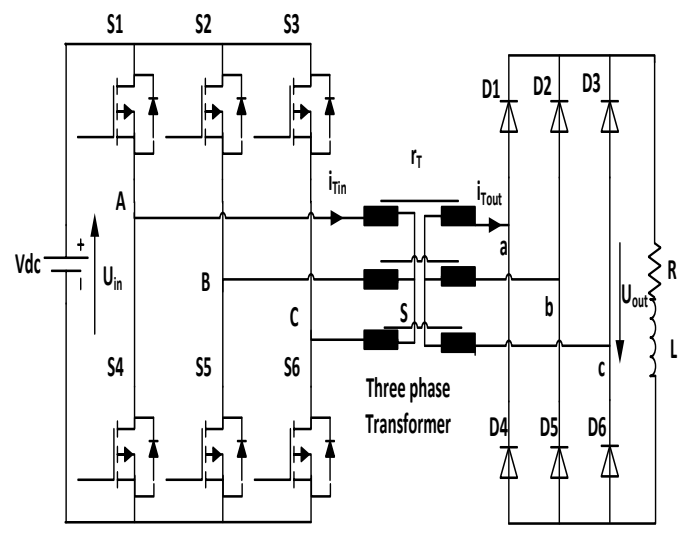

FIGURE 1. Circuit diagram of three-phase single active bridge DC-DC converter. 
converters are integrated with system networks, the power quality of the system is affected. In order to reduce these harmonics, a comparative analysis is made between conventional 150, 180, 120 modes for SAB3 [9-10] with 14 vector groups of transformer as shown in Table 1 .

\section{Review of Three-Phase Single Active Bridge DC-DC Converter}

Figure 1 shows the SAB3 topology. The SAB3 comprises an input inverter, a transformer, and an output diode rectifier. They are normally used for high power applications. In order to get three-phase output, three single-phase inverters can be connected in parallel. The gating signal of the three single-phase inverter should be advanced voltage [11-12]. Threephase inverter contains six switches. Switch may be IGBT, MOSFET, GTO, etc. depending upon the application; the diodes are connected across the s1 to s6 switches. The threephase inverter is operated at several modes. In this article, all modes of conduction are investigated [13-14].

\subsection{Design of an Inverter Switching Topology in MATLAB}

In all industrial application, variable frequency \& voltage require different applications. Three-phase full-bridge inverter is more popular than any other inverter topology. There are three modes of operation of three-phase inverter i.e. 120,150, and 180. Each mode is discussed in detail below [8]. In 120 Degree conduction mode of the inverter, each switch conducts for 120 Degree as shown in Figure 2. It is preferable for a delta connected load because it provides a six-step waveform across any phase. Only two switches are in conduction state at any instant. The conduction of different switches is listed in Figure 3. In 180-conduction mode of the inverter, each switch conducts for 180 Degree as shown in Figure 4. They are turned on at a regular interval of 60 degrees in the sequence of S1, S2, S3, S4, S5, and S6. Only three switches are in conduction state at any instant. The conduction of different switches is listed in Figure 5. In 150 Degree conduction mode of

TABLE 1. Vector group of transformer with phase shift

\begin{tabular}{llllll}
\hline \multicolumn{2}{l}{ H.T side delta connected } & H.T side star connected & & \\
\hline Sr. no & V.G & Phase shift & Sr. no & V.G & $\begin{array}{l}\text { Phase } \\
\text { shift }\end{array}$ \\
01 & Dd0 & 0 & 09 & Yy0 & 0 \\
02 & Dy1 & -30 & 10 & Yd1 & -30 \\
03 & Dy11 & +30 & 11 & Yd11 & +30 \\
04 & Dy5 & -150 & 12 & Yd5 & -150 \\
05 & Dy7 & +150 & 13 & Yd7 & +150 \\
06 & Dd6 & +180 & 14 & Yy6 & +180 \\
07 & Dd2 & -60 & & & \\
08 & Dd4 & -120 & & & \\
\hline
\end{tabular}




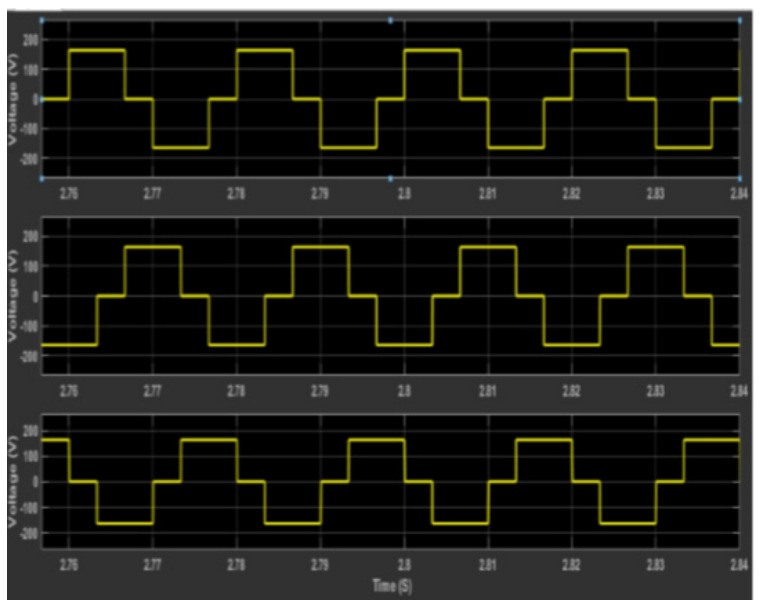

FIGURE 2. Phase voltages of three-phase inverter at primary side on 120 mode of conduction.

\begin{tabular}{|l|c|c|c|}
\hline S. no & $\begin{array}{c}\text { Conduction of } \\
\text { states }\end{array}$ & \multicolumn{2}{|c|}{ Conduction of switches } \\
\hline 1 & 0 to 60 & S1 & S6 \\
\hline 2 & 60 to120 & S1 & S2 \\
\hline 3 & 120 to180 & S2 & S3 \\
\hline 4 & 180 to 240 & S3 & S4 \\
\hline 5 & 240 to300 & S4 & S5 \\
\hline 6 & 300 to360 & S5 & S6 \\
\hline
\end{tabular}

FIGURE 3. Switching table of conduction of different states \& switches in 120 degree conduction mode of inverter.

the inverter, each switch conducts for 150 Degree. It has twelve steps, each of 30-Degree duration for completing one cycle of the output ac voltage as shown in Figure 6. In the 150-degree conduction mode of the inverter, a 30-degree dead period is provided between two switches, which are large enough to avoid short circuit on dc supply. It eliminates lower order harmonics largely. The conduction of different switches is listed in Figure 7.

\subsubsection{Total Harmonic Distortion}

Total harmonic distortion (THD) of a waveform is a quantity of the distortion present due to harmonics. Mathematically, it can be written as:

$$
T H D=\sqrt{I_{2}^{2}+I_{3}^{2}+\ldots \ldots \ldots \ldots I_{N}{ }^{2}}=\frac{\sqrt{\sum_{K=2}^{N} I_{N r m s}^{2}}}{I_{1 r m s}-f}
$$




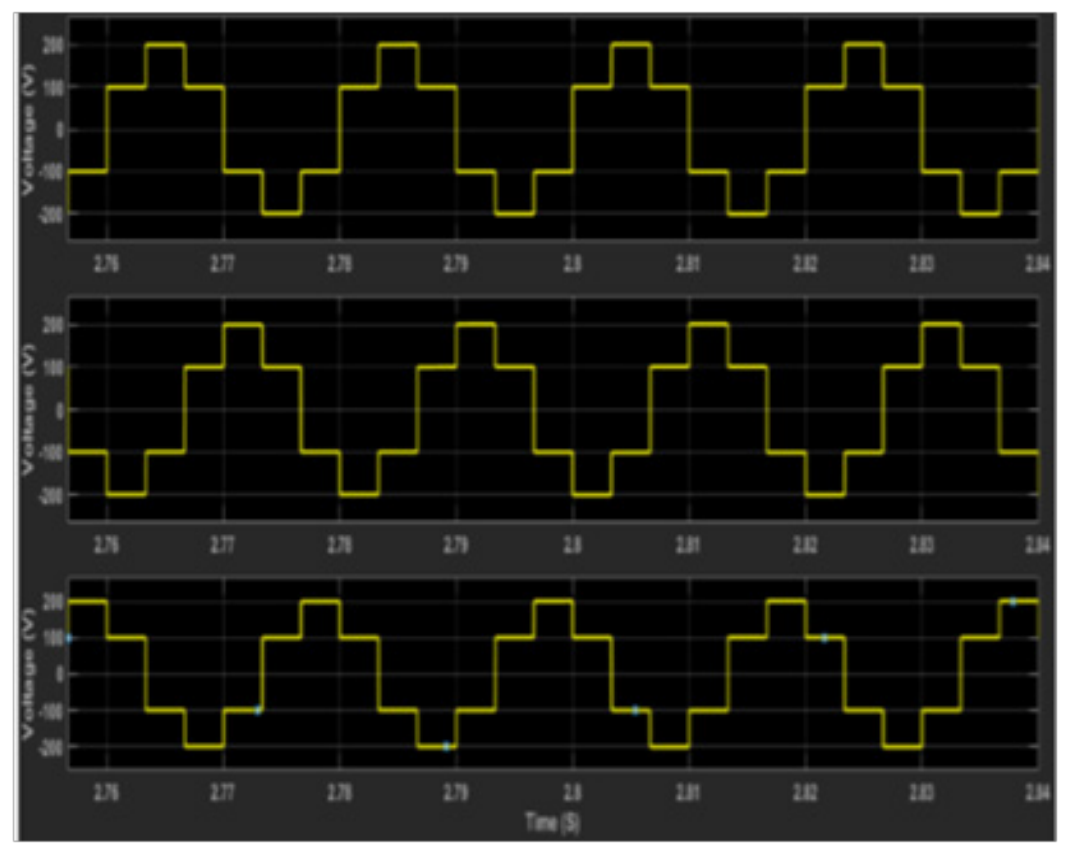

FIGURE 4. Phase voltages of three-phase inverter at primary side on 180 mode of conduction.

\begin{tabular}{|l|l|l|l|l|}
\hline $\begin{array}{l}\text { SR } \\
\text { NO }\end{array}$ & $\begin{array}{l}\text { Conduction } \\
\text { of states }\end{array}$ & \multicolumn{3}{|l|}{ Conduction of switches } \\
\hline 1 & 0 to 60 & S5 & S6 & S1 \\
\hline 2 & 60 to 120 & S6 & S1 & S2 \\
\hline 3 & 120 to 180 & S1 & S2 & S3 \\
\hline 4 & 180 to 240 & S2 & S3 & S4 \\
\hline 5 & 240 to 300 & S3 & S4 & S5 \\
\hline 6 & 300 to 360 & S4 & S5 & S6 \\
\hline
\end{tabular}

FIGURE 5. Switching table of conduction of different states \& switches in 180 degree conduction mode of inverter.

Irms is the RMS current of the Nth harmonics, and Irms $-f$ is the RMS current of the fundamental frequency.

\subsubsection{Review of Vector Groups of Transformer}

Three-phase power transformers and its windings with primary and secondary terminals are shown in Figure 8. It can be configured in many fashions to meet the application 


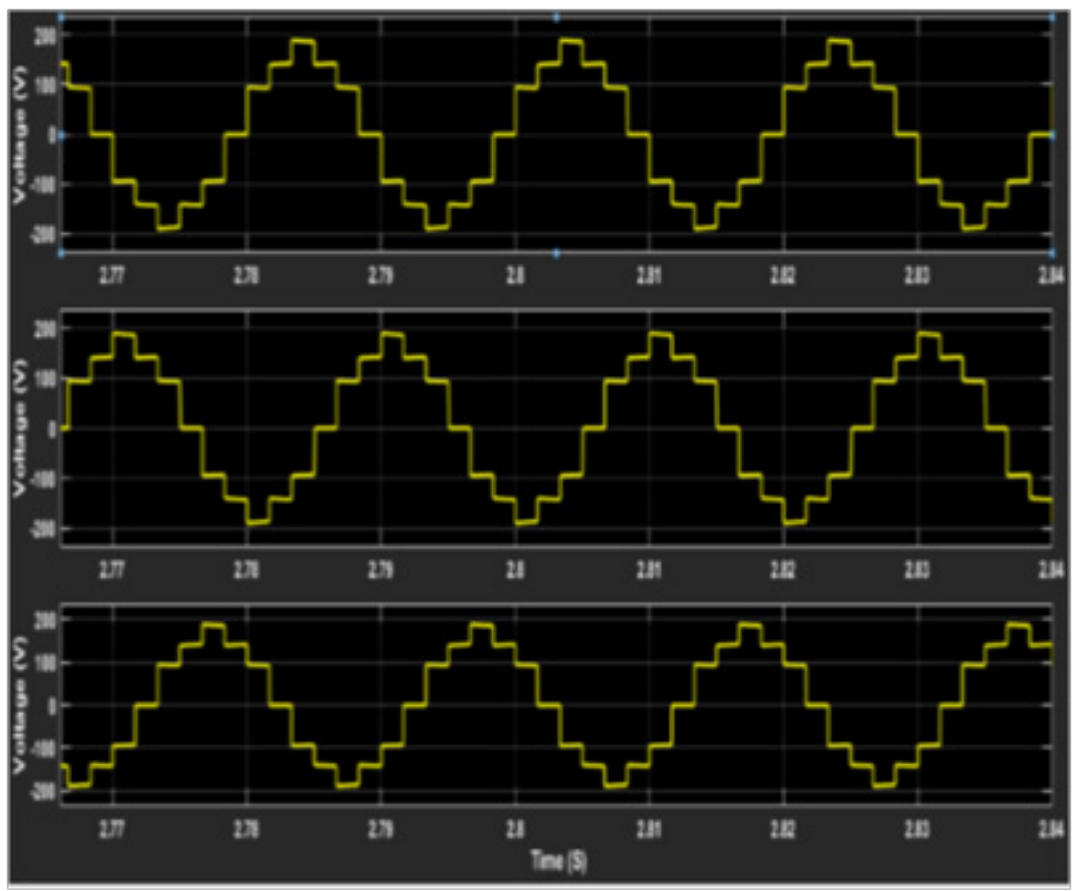

FIGURE 6. Phase voltages of three-phase inverter at primary side on 150 mode of conduction.

\begin{tabular}{|l|l|l|l|l|}
\hline SR & \multicolumn{2}{|l|}{$\begin{array}{l}\text { Conduction of } \\
\text { States }\end{array}$} & \multicolumn{3}{|l|}{ Conduction of switches } \\
\hline 1 & 0 to60 & S5 & S6 & S1 \\
\hline 2 & 60 to120 & S6 & S1 & S2 \\
\hline 3 & 120 to 180 & S1 & S2 & S3 \\
\hline 4 & 180 to 240 & S2 & S3 & S4 \\
\hline 5 & 240 to300 & S3 & S4 & S5 \\
\hline 6 & 300 to 360 & S4 & S5 & S6 \\
\hline
\end{tabular}

FIGURE 7. Switching table of conduction of different states \& switches in 150 degree conduction mode of inverter.

requirements. International Electro technical Commission (IEC), uses standard coding for each winding connection of a three-phase transformer called the transformer vector group, usually attached to the transformer body [12]. A phase shift can exist between two sidelines voltages vary in the step of $30^{\circ}$ for various connections. The phase shift between 


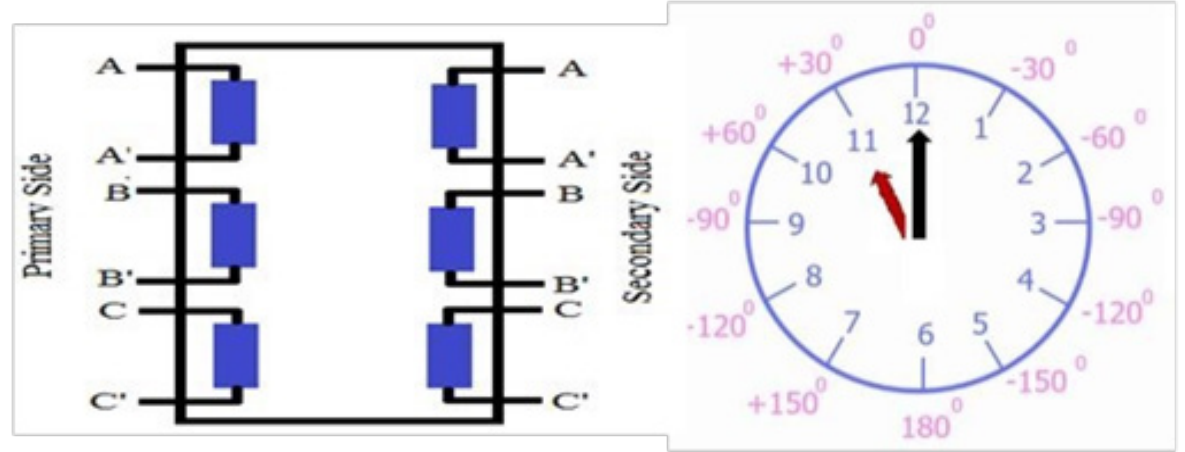

FIGURE 8. Three-phase transformer.

FIGURE 9. Concept of phase shift is always stationary at $12 \mathrm{O}$.

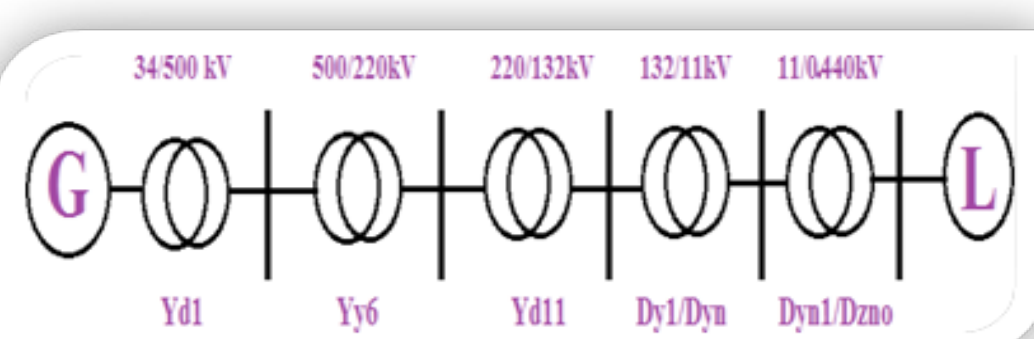

FIGURE 10. Transformer connections from generation to distribution levels.

the HT and LT line voltage is very similar to the clock system [15]. The minute needle is for (H.T) voltage and it as shown in Figure 9. Clock, and hour needle for (L.T) line voltage which moves clockwise (HT voltage leading) or anti-clockwise (LT voltage leading) concerning minute needle, that can be easily understood from Figure 9 [16]. For example, the vector group Yd11 shows the HT side is star connected, LT side is delta connected and 11 means phase shifts between the two-line voltages is $30^{\circ}$, LT line voltage leading HT line voltage.

\subsubsection{Importance of Transformer Vectors Groups}

The electrical distribution network's performance is very well concerned with the winding configuration of transformers. These have the harmonics canceling capability at PCC [17]. Either it is stability problem, parallel operation of these transformers or it is the control of real power flow in transmission network selection of a proper vector group at a strategic point for a specific mean has the significance responsibilities. Applications of various vector groups of transformers are depicted in Figure 10 which shows a single line diagram of the power system network. The generation side uses Yd or Dy standard vector group. 
Since transmission system voltage is very high and it is encountered to large unbalance loading, Dd0 or Dd6 usually selected to suppress unbalance loading ripples. Yd1 or Yd11 are suitable to step up voltage level and Dy1 or Dy11 are designed to step down voltage level.

\section{Simulation Model}

To investigate the performance of the SAB3 with various transformer vector groups, comprehensive simulations are performed on MATLAB/SIMULINK environment. The simulation model is shown in Figure 11.

\subsection{Assumptions}

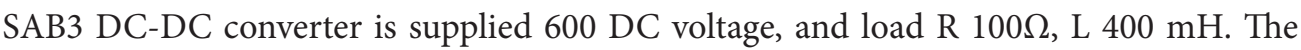
simulation of the SAB3 is confined in range of the core saturation limit.

\section{Results and Discussion}

The performance of SAB3 is analyzed utilizing FFT algorithm of MATLAB. Simulations are carried on both resistive and inductive loads. In order to compare the performance of SAB3 when connected through various vector group of transformers, first it is simulated

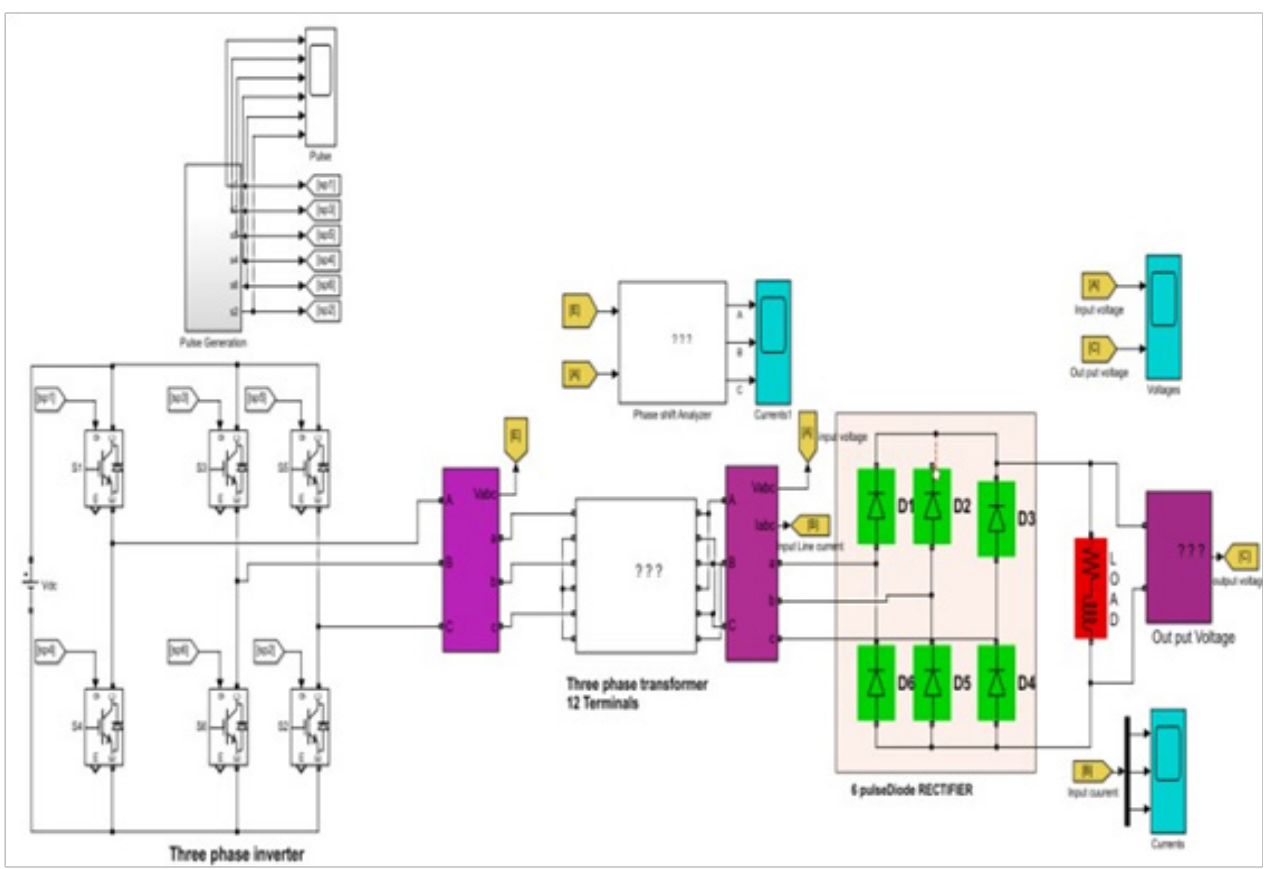

FIGURE 11. Simulation model of three-phase single active bridge DC-DC converter (SAB3). 


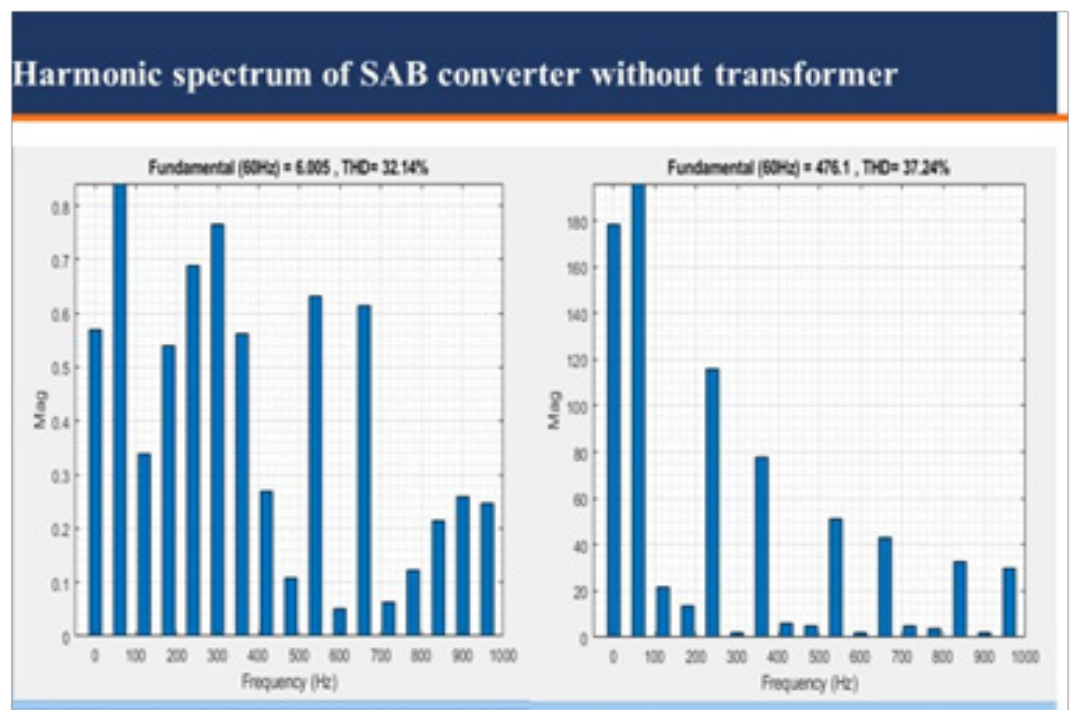

Simulated FFT results for both resistive and inductive load inductive load causes approximately $5.10 \%$ greater harmonics than resistive load.

FIGURE 12. Harmonic spectrum of SAB3 without transformer.

and analyzed alone to confirm the theoretical calculated THD of three-phase rectifier without connecting any transformer vector group.

\subsection{Direct Connected to Utility Supply}

Simulated FFT results of three-phase inverter current input to the rectifier without connecting transformer are shown in Figure 12 for both resistive and inductive load. Harmonics up to the 20th have been considered. It is observed from the result that inductive load causes approximately $5.10 \%$ greater harmonics than resistive load. In addition, inductive load is also responsible for injection of DC component in the system

\subsection{Connected Through Transformer}

\subsubsection{Current Comparison of Different Operating Modes with Vector Groups}

From Figure 13 and Table 2,4,6, it is concluded that in case of 150 mode of conduction of SAB3 converter, average current THD of all vector group at resistive load is $23.74 \%$ which is the reduced THD $8.37 \%, 10.5 \%$ in case of 120,180 mode of conduction, respectively. From Figure 14 and Tables 2,4,6, it is concluded that in case of inductive load average current THD 150 mode of conduction of SAB3 converter of all vector group is $18.87 \%$ which is the reduction THD $13.12 \%, 14.82 \%$ in case of 120,180 mode of conduction, respectively. 


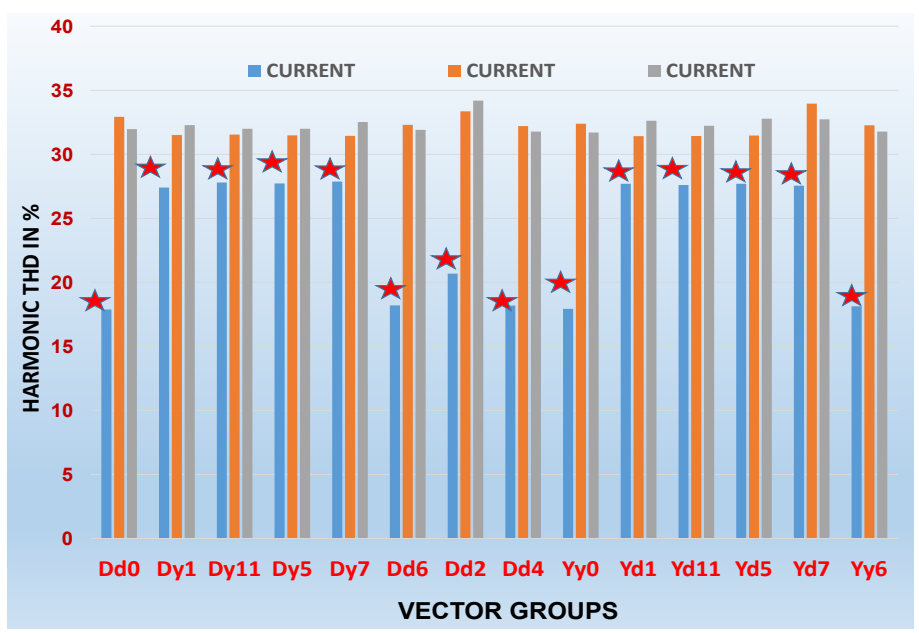

FIGURE 13. Current comparison of resistive load all vector group with all modes.

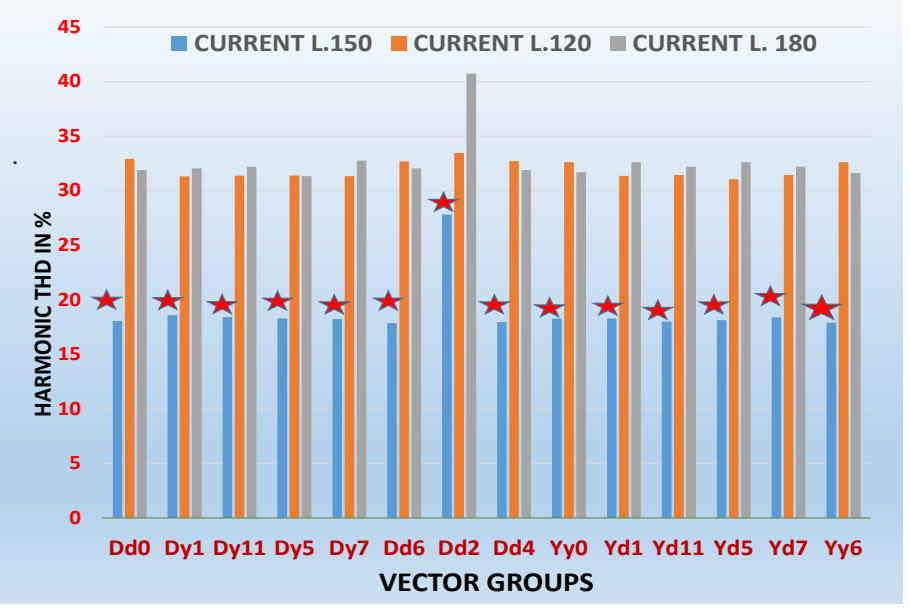

FIGURE 14. Current comparison of inductive load all vector group with all modes.

\subsubsection{Voltage Comparison of Different Operating Modes with Vector Groups}

From Figure 15, it is concluded that in case of voltage average THD of resistive load in 150 mode of conduction of SAB3 converter of all vector group is $16.93 \%$ which is the reduction THD $14.48 \%, 12.47 \%$ in case of 120, 180 mode of conduction, respectively. From Figure 16 , it is concluded that in case of inductive load average voltage THD of 150 mode of conduction of SAB3 converter of all vector group is $17.93 \%$ which is the reduction THD $14.12 \%, 12.11 \%$ in case of 120,180 mode of conduction, respectively. 


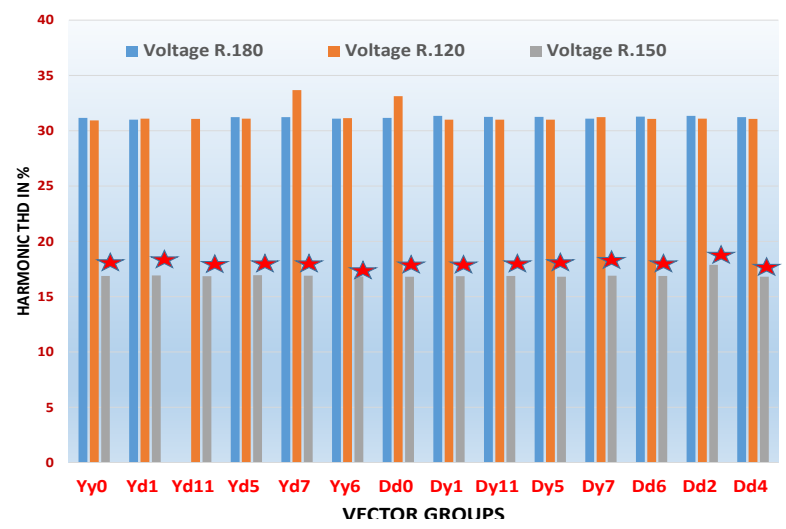

FIGURE 15. Voltage comparison of resistive load all vector group with all modes.

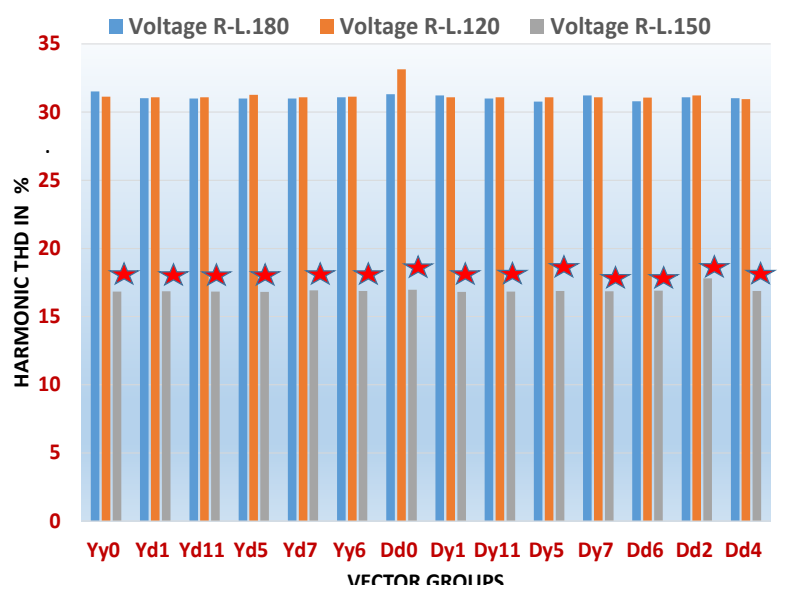

FIGURE 16. Voltage comparison of inductive load all vector group with all modes.

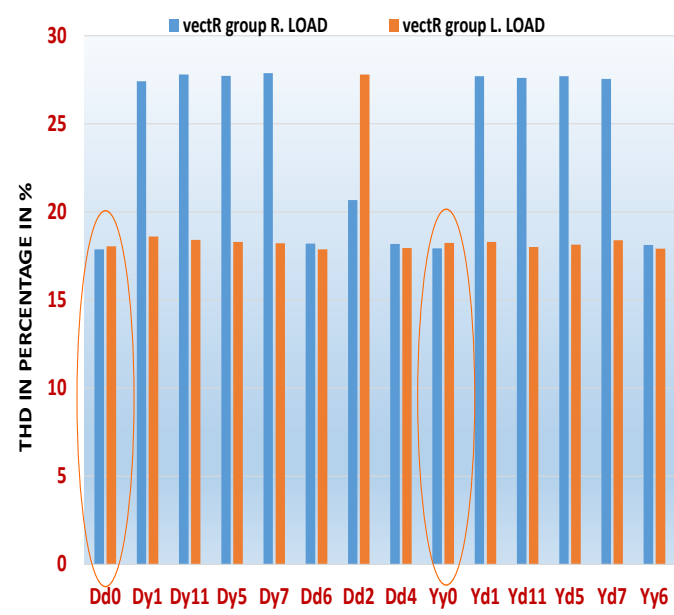

I/ErTnd edon InC

FIGURE 17. Current comparison of resistive and inductive load of 150 mode of conduction. 


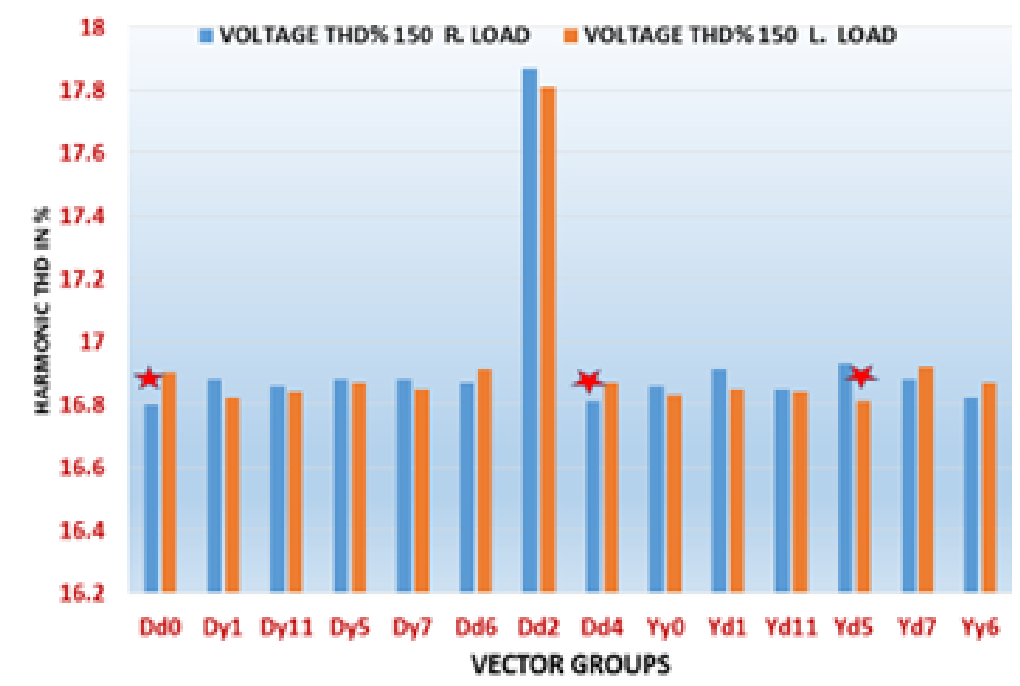

FIGURE 18. Voltage comparison of resistive and inductive load of 150 mode of conduction.

TABLE 2. Current THD results of SAB3 with 150 mode with transformer vector group

\begin{tabular}{lcrcc}
\hline Sr. no & Vector group & Phase shift & \multicolumn{2}{c}{ Current THD\% } \\
\cline { 3 - 5 } & & & R & R-L \\
\hline 1 & Yy0 & 0 & 17.93 & 18.25 \\
2 & Yd1 & -30 & 27.70 & 18.29 \\
3 & Yd11 & +30 & 27.60 & 18.01 \\
4 & Yd5 & -150 & 27.70 & 18.14 \\
5 & Yd7 & +150 & 27.56 & 18.39 \\
6 & Yy6 & +180 & 18.13 & 17.91 \\
7 & Dd0 & 0 & 17.88 & 18.04 \\
8 & Dy1 & -30 & 27.41 & 18.60 \\
9 & Dy11 & +30 & 27.80 & 18.42 \\
10 & Dy5 & -150 & 27.73 & 18.29 \\
11 & Dy7 & +150 & 27.87 & 18.23 \\
12 & Dd6 & +180 & 18.21 & 17.87 \\
13 & Dd2 & -60 & 20.68 & 27.81 \\
14 & Dd4 & -120 & 18.19 & 17.95 \\
\hline
\end{tabular}

TABLE 3. Voltage THD results of SAB3 with 150 mode with transformer vector groups

\begin{tabular}{|c|c|c|c|c|}
\hline \multirow[t]{2}{*}{ Sr. no } & \multirow[t]{2}{*}{ Vector groups } & \multirow[t]{2}{*}{ Phase shift } & \multicolumn{2}{|c|}{ Voltage THD\% } \\
\hline & & & $\mathbf{R}$ & R-L \\
\hline 1 & Yy0 & 0 & 16.86 & 16.83 \\
\hline 2 & Yd1 & -30 & 16.91 & 16.85 \\
\hline 3 & Yd11 & +30 & 16.85 & 16.84 \\
\hline 4 & Yd5 & -150 & 16.93 & 16.81 \\
\hline 5 & Yd7 & +150 & 16.88 & 16.92 \\
\hline 6 & Yy6 & +180 & 16.82 & 16.87 \\
\hline
\end{tabular}


Comparative Analysis of Three-Phase Single Active Bridge DC-DC Converter with Different Mode of Conduction with Transformer Vector Groups

\begin{tabular}{llrll}
\hline 7 & Dd0 & 0 & 16.8 & 16.9 \\
8 & Dy1 & -30 & 16.84 & 16.82 \\
9 & Dy1 & +30 & 16.86 & 16.84 \\
10 & Dy5 & -150 & 16.80 & 16.87 \\
11 & Dy7 & +150 & 16.88 & 16.85 \\
12 & Dd6 & +180 & 16.87 & 16.91 \\
13 & Dd2 & -60 & 17.87 & 17.81 \\
14 & Dd4 & -120 & 16.81 & 16.87 \\
\hline
\end{tabular}

TABLE 4. Current THD results of SAB3 with 120 mode with transformer vector groups

\begin{tabular}{lcrcc}
\hline Sr. no & Vector groups & Phase shift & \multicolumn{2}{c}{ Current THD\% } \\
\cline { 3 - 5 } & & & R & R-L \\
\hline 1 & Yy0 & 0 & 32.39 & 32.59 \\
2 & Yd1 & -30 & 31.42 & 31.36 \\
3 & Yd1 & +30 & 31.43 & 31.44 \\
4 & Yd5 & -150 & 31.47 & 31.05 \\
5 & Yd7 & +150 & 33.96 & 31.44 \\
6 & Yy6 & +180 & 32.27 & 32.59 \\
7 & Dd0 & 0 & 32.93 & 32.92 \\
8 & Dy1 & -30 & 31.51 & 31.31 \\
9 & Dy11 & +30 & 31.54 & 31.39 \\
10 & Dy5 & -150 & 31.48 & 31.39 \\
11 & Dy7 & +150 & 31.44 & 31.34 \\
12 & Dd6 & +180 & 32.30 & 32.67 \\
13 & Dd2 & -60 & 33.36 & 33.45 \\
14 & Dd4 & -120 & 32.20 & 32.71 \\
\hline
\end{tabular}

TABLE 5. Voltage THD results of SAB3 with 120 mode with transformer vector groups

\begin{tabular}{lcrcc}
\hline Sr no & Vector group & Phase shift & \multicolumn{2}{c}{ Voltage THD\% } \\
\cline { 4 - 5 } & & & R & R-L \\
\hline 1 & Yy0 & 0 & 30.93 & 31.13 \\
2 & Yd1 & -30 & 31.08 & 31.08 \\
3 & Yd1 & +30 & 31.07 & 31.08 \\
4 & Yd5 & -150 & 31.08 & 31.26 \\
5 & Yd7 & +150 & 33.68 & 31.08 \\
6 & Yy6 & +180 & 31.14 & 31.13 \\
7 & Dd0 & 0 & 33.13 & 33.14 \\
8 & Dy1 & -30 & 31.01 & 31.09 \\
9 & Dy11 & +30 & 31.00 & 31.08 \\
10 & Dy5 & -150 & 31.01 & 31.09 \\
11 & Dy7 & +150 & 31.22 & 31.08 \\
12 & Dd6 & +180 & 31.07 & 31.07 \\
13 & Dd2 & -60 & 31.08 & 31.22 \\
14 & Dd4 & -120 & 31.07 & 30.95 \\
\hline
\end{tabular}


TABLE 6. Current THD results of SAB3 with 180 mode with transformer vector groups

\begin{tabular}{lcrrr}
\hline Sr no & Vector groups & Phase shift & \multicolumn{2}{c}{ Current THD\% } \\
\cline { 3 - 5 } & & & $\mathbf{R}$ & R-L \\
\hline 1 & Yy0 & 0 & 31.70 & 31.69 \\
2 & Yd1 & -30 & 32.62 & 32.60 \\
3 & Yd11 & +30 & 32.23 & 32.20 \\
4 & Yd5 & -150 & 32.78 & 32.60 \\
5 & Yd7 & +150 & 32.73 & 32.20 \\
6 & Yy6 & +180 & 31.77 & 31.62 \\
7 & Dd0 & 0 & 31.97 & 31.89 \\
8 & Dy1 & -30 & 32.28 & 32.05 \\
9 & Dy11 & +30 & 31.99 & 32.20 \\
10 & Dy5 & -150 & 31.99 & 31.32 \\
11 & Dy7 & +150 & 32.52 & 32.75 \\
12 & Dd6 & +180 & 31.91 & 32.04 \\
13 & Dd2 & -60 & 34.19 & 40.74 \\
14 & Dd4 & -120 & 31.78 & 31.88 \\
\hline
\end{tabular}

TABLE 7. Voltage THD results of SAB3 with 180 mode with transformer vector groups

\begin{tabular}{lcrcc}
\hline \multirow{2}{*}{ Sr no } & Vector groups & Phase shift & \multicolumn{2}{c}{ Voltage THD\% } \\
\cline { 3 - 5 } & & & $\mathbf{R}$ & R-L \\
\hline 1 & Yy0 & 0 & 31.15 & 31.51 \\
2 & Yd1 & -30 & 31.00 & 31.01 \\
3 & Yd11 & +30 & $31 . .00$ & 31.00 \\
4 & Yd5 & -150 & 31.22 & 31.00 \\
5 & Yd7 & +150 & 31.23 & 31.00 \\
6 & Yy6 & +180 & 31.08 & 31.08 \\
7 & Dd0 & 0 & 31.15 & 31.30 \\
8 & Dy1 & -30 & 31.34 & 31.23 \\
9 & Dy11 & +30 & 31.25 & 31.00 \\
10 & Dy5 & -150 & 31.25 & 30.78 \\
11 & Dy7 & +150 & 31.08 & 31.22 \\
12 & Dd6 & +180 & 31.28 & 30.80 \\
13 & Dd2 & -60 & 31.34 & 31.08 \\
14 & Dd4 & -120 & 31.22 & 31.01 \\
\hline
\end{tabular}

From the results, it is concluded that 150 mode of conduction of SAB3 converter gives lesser value of THD in terms of current and voltage for both resistive and inductive load as shown in Tables 3,5,7.

\subsubsection{Voltage and Current Comparison of 150 Mode of Operation with Vector Groups}

In Figures 17 and 18, it is concluded that in case of 150 mode of operation, at resistive load vector group Dd0 and Yy0 have best harmonics compressing capability of $14.26 \%$ and 
$14.2 \%$, respectively. In case of inductive load preference must be given to Dy6, Dd4, and Yd6 which resourced current THD 19.37\%, 19.29\%, and 19.33\%, respectively Table 2-3.

\section{Conclusion}

Harmonics produced due to three-phase single active bridge SAB3 have their own natural spectrum, consequently mitigation of harmonics in the system from SAB3 and selecting a suitable and reliable method will be cost effective. This study shows the comparative analysis of SAB3 with various vector groups of transformers with different operating modes of three-phase inverter in terms of total harmonics distortion of voltage and current. From the above results, it is concluded that in 150 mode of conduction of SAB3 converter gives lesser value of THD in terms of current and voltage for both resistive and inductive load.

A compromise is need to be made between current THD and voltage THD that is to be minimized, since from the results it is clear that for resistive load vector groups Dd0 or Yy0 efficiently reduced harmonics than other vector groups but at the same time Dd2 has raised voltage THD beyond the standard limit. Thus it is recommended that when such a load which is very sensitive to voltage change connected at PCC, then vector group Dd2 should not be used between three-phase inverter and rectifier.

\section{Acknowledgement}

The authors are thankful to Mehran University of Engineering and Technology Jamshoro, (MUET) Pakistan, for providing all needed services for the achievement of this research work.

\section{References}

1. Sang Y, Junyent-Ferré A, Green TC, editors. Transformer design in a medium voltage DC/DC converter for a DC collection network. In: 2017 19th European conference on power electronics and applications. 2017. https://doi.org/10.23919/EPE17ECCEEurope.2017.8099269

2. Jacobs J, Thommes M, De Doncker R, editors. A transformer comparison for three-phase single active bridges. In: 2005 European conference on power electronics and applications. 2005. https://doi.org/10.1109/EPE.2005.219599

3. Sommer C, Mertens A, Larrazabal I, Kortazar I, editors. Analytical investigation of the threephase single active bridge for offshore applications. In: 2016 18th European conference on power electronics and applications (EPE'16 ECCE Europe). 2016. https://doi.org/10.1109/ EPE.2016.7695590

4. Park K, Chen Z, editors. Analysis and design of a parallel-connected single active bridge DC-DC converter for high-power wind farm applications. In: 2013 15th European conference on power electronics and applications (EPE). 2013. https://doi.org/10.1109/EPE.2013.6631854

5. Boudrias J, editor. Harmonic mitigation, power factor correction and energy saving with proper transformer and phase shifting techniques. In: Canadian conference on electrical and computer engineering. 2004. https://doi.org/10.1109/CCECE.2004.1344974 
6. Zahira R, Fathima AP. A technical survey on control strategies of active filter for harmonic suppression. Procedia Engineering. 2012; 30, 686-693. https://doi.org/10.1016/j. proeng.2012.01.915

7. Ting Y, De Haan S, Ferreira B. Modular single-active bridge DC-DC converters: efficiency optimization over a wide load range. IEEE Industry Applications Magazine. 2016; 22(5), 43-52. https://doi.org/10.1109/MIAS.2015.2459086

8. Patel DK, Chauhan J, Patel AR, Mishra N, editors. A user friendly simulation for transformer vector group. In: 2012 international conference on communication systems and network technologies. 2012.https://doi.org/10.1109/csnt.2012.178

9. Meng F, Gao L, Yang S, Yang W. Effect of phase-shift angle on a delta-connected autotransformer applied to a 12-pulse rectifier. IEEE Transactions on Industrial Electronics. 2015; 62(8), 46784690. https://doi.org/10.1109/TIE.2015.2405058

10. Mahar MA, Uqaili MA, Larik AS. Harmonic analysis of ac-dc topologies and their impacts on power systems. Mehran University Research Journal of Engineering \& Technology. 2011; 30(1), 173-178.

11. Bhutia B, Ali S, Tiadi N. Design of three phase PWM voltage source inverter for photovoltaic application. International Journal of Innovative Research in Electrical, Electronics, Instrumentation and Control Engineering. 2014; 2(4), 1364-1367. https://doi.org/10.1109/ICCCE.2016.43

12. Chokkalingham B, Padmanaban S, Blaabjerg F. Investigation and comparative analysis of advanced PWM techniques for three-phase three-level NPC-MLI drives. Electric Power Components and Systems. 2018; 46(3), 258-269. https://doi.org/10.1080/15325008.2018.14451 42

13. Mahar M, Abro M, Larik A. Artificial neural network control of sab dc/dc converter. Mehran University Research Journal of Engineering and Technology. 2009; 28(4), 591-592. https://inis. iaea.org/search/search.aspx?orig_q=RN:41000959

14. Liu H, Dahidah M, Naayagi RT, Armstrong M, Yu J. Unidirectional DC/DC modular multilevel converter for offshore wind farm with the control strategy based on stationary frame. The Journal of Engineering. 2019; 2019(17), 4309-4314. https://doi.org/10.1049/joe.2018.8003

15. Lawhead L, Hamilton R, Horak J, editors. Three phase transformer winding configurations and differential relay compensation. In: 60th annual Georgia tech protective relay conference. 2006. https://doi.org/10.1109/PCICON.2007.4365778

16. Katuara S, Gemmani S. Simulink analysis of vector groups of transformers installed at $132 \mathrm{kV}$ grid station Qasimabad Hyderabas and their effects on system operation. International Journal of Science and Research. 2016, 1697-1701. http://www.academia.edu/download/43630603/ NOV152593.pdf

17. Mahar MA. Analysis and design of neural network controller of single active bridge converter [Doctoral dissertation]. Mehran University of Engineering \& Technology: Jamshoro. http://prr. hec.gov.pk/jspui/handle/123456789/1685 